\title{
SISTEMA BIRADS: \\ DESCIFRANDO EL INFORME MAMOGRÁFICO
}

César Augusto Poveda S. MD*

\section{Resumen}

Este artículo es una revisión del informe mamográfico aplicando el manual BIRADS, el cual cada vez tiene mayor uso, importancia y difusión no sólo entre los radiólogos, sino para todos los médicos que intervienen en la atención de la patología mamaria.

Palabras clave: mamografías, informe, sistema BIRADS, oncología.

Abreviaturas: VPP, valor predictivo positivo; INC, Instituto Nacional de Cancerología.

\section{BIRADS SYSTEM FOR MAMMOGRAPHIC INTERPRETATION}

\section{Abstract}

This article is a review of mammographic interpretation using the BIRADS system. Its practice, importance and diffusion have increased not only among radiologists but within referring physicians.

Key words: mammographies, report, BIRADS system, oncology.

\section{Introducción}

La palabra BIRADS corresponde al acrónimo en inglés de "Breast Imaging Reporting And Data System" que traduce Sistema de Informes y Registro de Datos de Imagen de la Mama. Es un manual producto del esfuerzo colaborativo entre diferentes entidades públicas y privadas norteamericanas como el American College of Radiology (ACR), Centers for Disease Control and Prevention (CDC), National Cancer Institute (NCI),
Food and Drug Administration (FDA), American College of Surgeons (ACS), American Medical Association (AMA) y American College of Pathologists $(A C P)$, que a través de varios comités recogieron la preocupación que manifestaron en la década de los ochenta los médicos tratantes de pacientes con enfermedad mamaria sobre la alta variabilidad, ambigüedad y deficiente calidad en la emisión de los informes mamográficos. 
Así, en 1995 se publica la primera edición de este manual dirigida a los médicos radiólogos. Aún está vigente la cuarta edición de noviembre de $2003,{ }^{1}$ documento dinámico en el que el ACR a través del Breast Cancer Committee admite sugerencias y dudas, las cuales resuelve y aclara a través de publicaciones científicas. ${ }^{2}$ En la actualidad el manual se ha convertido en un documento de obligatoria consulta para todo el personal médico que interviene en el proceso de diagnóstico, tratamiento y seguimiento de mujeres con patología mamaria.

El manual BIRADS busca entre otras cosas estandarizar el reporte mamográfico, mejorando su calidad y la comunicación entre médicos tratantes, radiólogos y pacientes, y en forma secundaria se convierte en una poderosa herramienta de investigación, auditoría y seguimiento.

En Estados Unidos a través de una ley emitida por el Congreso, se estableció el programa de estándares de calidad en mamografía ( $M Q S A$ por sus siglas en inglés), ${ }^{3}$ que establece la obligatoriedad para emitir la valoración de BIRADS en toda mamografía como parte de los requisitos para la certificación y habilitación del centro diagnóstico en donde se tome el estudio. Esta exigencia es opcional para ecografía y resonancia magnética. En el país no existe legislación similar, aunque la Sociedad de Radiología de Colombia recomienda su empleo a todos sus asociados. A pesar de la amplia difusión, preocupa el desconocimiento y/o uso inexacto de la filosofía y alcances del manual en los médicos tratantes y entre los radiólogos mismos. Lehman en 2002 revisó 82.000 mamografías encontrando $3 \%$ de incongruencias entre la categorización BIRADS y la recomendación dada por el radiólogo, indicando que existen aún esfuerzos que hacer para la difusión y comprensión del manual BIRADS. ${ }^{4}$ En Colombia los primeros esfuerzos para su conocimiento datan de finales de los años noventa. ${ }^{5}$ A continuación se hace una revisión práctica del manual BIRADS y se discuten los principales errores que encuentra el clínico y el radiólogo en la práctica diaria.

\section{Estructura del manual BIRADS}

Se divide en secciones: la primera establece el léxico, donde se detalla la semiología imagenológica para la descripción de los hallazgos que debe emplear el radiólogo en sus informes, en la segunda se indica la forma de elaborar y comunicar el reporte y en la tercera se establecen las bases para que el centro de diagnóstico imagenológico construya una auditoría básica, que permita el seguimiento del rendimiento diagnóstico de las mamografías tomadas en dicho lugar. Por último, quedan cuatro secciones más, de menor relevancia, en las que se dan recomendaciones sobre el uso, orientación en casos especiales, ejemplos de los formularios de recolección de datos y casos ilustrativos.

\section{Léxico}

A. El primer concepto del léxico es nódulo, que se define como toda imagen redondeada u ovoide que tiene representación en dos diferentes proyecciones mamográficas del mismo seno. Si la imagen se evidencia en una sola, se denomina asimetría. En los nódulos se evalúan la morfología, contornos y densidad.

La morfología se categoriza en alguno de los siguientes cuatro: redondeado, ovalado, lobulado, o irregular, este último es la de mayor relevancia ya que las neoplasias en general se manifiestan así. Luego se deben evaluar los contornos de cada nódulo que se clasifican en cinco: circunscritos (al menos el $75 \%$ de su perímetro debe estar bien delimitado y el resto superpuesto a tejido mamario), microlobulados, ocultos (se emplea cuando el radiólogo cree que es bien delimitado pero está enmascarado en tejido mamario), borrosos (en los que al menos una porción del perímetro está mal definida pero no debido a parénquima adyacente) y espiculados, que es un signo semiológico que da valor predictivo positivo (VPP) de malignidad del $93 \%{ }^{6}$

Por último, se debe considerar la densidad del nódulo. Se toma como referencia para comparar con un volumen similar de tejido mamario. Se categorizan cuatro: hiperdenso, isodenso, hipodenso sin grasa e hipodenso con grasa. Las neoplasias corresponden a 
proliferaciones celulares descontroladas en un área focal de volumen, por lo que se manifiestan a menudo como imágenes hiperdensas (radio-opacas o "blancas") y con menor frecuencia son isodensas. En general toda lesión en mamografía con densidad grasa se considera benigna.

Desde el punto de vista semiológico se deben diferenciar asimetría, asimetría focal, nódulo y asimetría global. La asimetría corresponde al acúmulo de parénquima mamario que se ve en una sola proyección, las dos siguientes se representan en dos proyecciones, pero la asimetría focal tiene perdida al menos la convexidad de uno de sus bordes y el nódulo tiene todos sus contornos convexos. La asimetría focal sólo se identifica en un cuadrante y se debe hacer seguimiento ya que puede representar la única manifestación de una neoplasia lobular. La asimetría global ocupa más de un cuadrante, no debe ser palpable y casi siempre representa un acúmulo de parénquima mamario.

B. La segunda consideración del léxico son las calcificaciones que se subdividen en tres categorías. La primera corresponde a las lesiones típicamente benignas que nos dan un $100 \%$ de certeza de benignidad, y son las calcificaciones cutáneas, las vasculares, las groseras o en "palomitas de maíz" por fibroadenomas, las calcificaciones en "vara" por mastitis de células plasmáticas, las redondeadas-puntiformes (menores de $0.5 \mathrm{~mm}$ ), las de centro radiolúcido, las de aspecto en "cáscara de huevo" o "anillo", aquellas en "lechada de calcio", las que se ven en suturas y las distróficas.

La siguiente categoría son las calcificaciones con sospecha intermedia, entre las cuales se incluyen las amorfas o indiferenciadas y las heterogéneas groseras.

Las calcificaciones altamente sospechosas de malignidad se subdividen a su vez en pleomorfas finas y en lineales finas ramificadas. Este grupo confiere el mayor grado de sospecha y su aspecto representa el molde irregular (el negativo) de los conductos obstruidos con proceso neoplásico en sus paredes.

Por último, luego de clasificarlas en alguna de las tres categorías anteriores, se describen los patrones de distribución que son cinco: difusas/dispersas en casi todo el seno, que suelen ser benignas, las regionales que ocupan al menos dos centímetros cúbicos de tejido mamario que suelen corresponder a un cuadrante, las agrupadas en cúmulos que se definen como al menos cinco microcalcificaciones en menos de $1 \mathrm{cc}$ de tejido mamario, las lineales o en "fila india" que por lo regular representan calcificaciones dentro de un conducto elevando su grado de sospecha, y las segmentarias ubicadas en un solo cuadrante, recordando un lobulillo, que si se suma a la alteración en su morfología dan alto grado de sospecha.

C. Distorsión de la arquitectura, es la tercera consideración del léxico e implica la presencia de densidades lineales que se irradian desde un solo punto, asociadas o no con un nódulo y pueden ser secundarias a neoplasia, necrosis grasa o antecedente quirúrgico. Como hallazgo único tiene un VPP de 93\%.

D. Casos especiales corresponden a hallazgos que por lo general determinan BIRADS 2, se describen hallazgos mamográficos específicos a considerar: estructura tubular asimétrica (conducto solitario dilatado) que si es un hallazgo aislado no tiene significancia patológica, ganglios linfáticos intramamarios, asimetría global (parénquima mamario que ocupa más de un cuadrante, no palpable) y asimetría focal (parénquima mamario que ocupa menos de un cuadrante, no palpable y que no cumple criterios de nódulo).

E. Hallazgos asociados se refiere a cambios mamográficos relacionados con neoplasia maligna como la retracción cutánea, la del pezón (en ausencia de otros hallazgos no es signo de malignidad), el engrosamiento cutáneo (normal: menor o igual a $2 \mathrm{~mm}$ de espesor) que puede ser focal o difuso, engrosamiento trabecular (de los septos fibrosos de la mama), lesiones cutáneas y adenopatías axilares.

Los hallazgos se deben describir en forma estandarizada, de tal manera que se usa la localización horaria, describiendo en qué cuadrante y su profundidad, la cual se divide en tercio anterior, medio y posterior. En la Tabla 1 se resume el léxico. 


\section{Tabla I. Léxico BIRADS}

\section{Nódulo}

A. Morfología

I. Redondeado

2 Ovalado

3. Lobulado

4. Irregular

B. Contornos

I. Circunscritos

2 Microlobulados

3. Ocultos

4. Borrosos

5. Espiculados

\section{Densidad}
I. Hiperdenso
2 Isodenso
3. Hipodenso sin grasa
4. Hipodenso con grasa

\section{Calcificaciones}

\section{A Típicamente benignas \\ B Sospecha intermedia \\ C. Altamente sospechosas de malignidad}

I. Pleomorfas finas

2 Lineales finas ramificadas

\section{Patrón de distribución}

I. Difusas/dispersas

2. Regionales

3. Agrupaciones en cúmulos

4. Lineales

5. Segmentarias

\section{Distorsión de la arquitectura}

\section{Casos especiales}

\section{Hallazgos asociados}

\section{Reporte}

Todo reporte mamográfico debe constar de cinco partes (Tabla 2). En la primera se debe resumir en forma concisa y clara la indicación del procedimiento, incluyendo tratamientos recibidos y cuando se dispone de estudios previos se deben registrar, incluyendo la fecha. Estos datos muchas veces no están disponibles porque la solicitud médica en general no las trae, limitando en forma importante la interpretación por parte del radiólogo. Luego sigue la composición de la mama en la que se hace un análisis global de las proyecciones radiográficas obtenidas, describiendo la cantidad, densidad y distribución del parénquima mamario. En general éste es simétrico en densidad y distribución. Después se describen los hallazgos significativos que sugieran malignidad como lo son: nódulos, distorsión arquitectural (de los ligamentos de Cooper) y las microcalcificaciones. Siempre que existan estudios previos se debe dejar consignado en el informe que están disponibles y que se usaron para determinar si hubo cambios evolutivos.

Con todo lo anterior se emite la impresión global o categorización BIRADS, que tiene enlazado, a diferencia de otros tipos de informe radiográfico, una recomendación establecida con claridad en el manual, acorde al BIRADS conceptuado.

\section{Tabla 2. Estructura del informe mamográfico}

I. Indicación.

2. Descripción: distribución, simetría, composición.

3. Descripción de hallazgo significativo:

- Nódulo.

- Calcificaciones.

- Distorsión arquitectural.

- Casos especiales.

4. Comparar con estudios previos.

5. Impresión global (categorización BIRADS).

Recomendación 


\section{Categorías BIRADS}

Existen dos tipos de categorías BIRADS, transitoria y definitivas (Tabla 3). En el primer grupo está sólo la categoría 0 (valoración incompleta), en la que el radiólogo con las proyecciones y datos clínicos disponibles no logra establecer una conclusión y sugiere al médico tratante a través del informe mamográfico la realización de estudios adicionales, como por ejemplo: ecografía mamaria o proyecciones mamográficas especiales que incluyan compresión focal o magnificaciones. Por lo general corresponde a senos con parénquima abundante, denso, que oculta lesiones focales (Figuras 1a y 1b) o a nódulos redondeados inespecíficos (Figuras 2a y 2b). También se incluye, si así es el caso, que el médico radiólogo puede colocar la mamografía en categoría 0 si el paciente informa que dispone de estudios previos para comparar pero que no los anexa en el momento.

Luego siguen las definitivas que se inician con la categoría 1 (estudio negativo): los hallazgos mamográficos no muestran anormalidad e implica un riesgo de malignidad del $0 \%{ }^{7,8}$ por lo que no requiere estudios complementarios (Figura 3). La recomendación original del manual es continuar con tamizaje mamográfico, que en Estados Unidos corresponde a seguimiento mamográfico anual. El Instituto Nacional de Cancerología organismo del orden nacional referente para el manejo integral del cáncer en Colombia, cuenta entre sus prioridades el cáncer de seno, por lo que en 2006 emitió las guías de detección temprana de cáncer ${ }^{9}$ en las que luego de una evaluación de la literatura médica disponible hasta ese momento y empleando la metodología de la medicina basada en la evidencia, propuso entre otras recomendaciones, que para un país con incidencia intermedia de cáncer de seno como el nuestro (30 por 100.000 mujeres), conviene realizar tamizaje mamográfico cada dos años en mujeres de 50 a 69 años, dejando los restantes rangos de edad sin recomendación ante la insuficiente evidencia. En 2008 el INC inició un estudio piloto multicéntrico ${ }^{10}$ que busca validar estas recomendaciones, el cual está en desarrollo.

\section{Tabla 3. Categorías BIRADS}

Transitoria

0: Valoración incompleta: se requieren imágenes adicionales para que sea adecuada.

\section{Definitivas}

I: Mamografía negativa: control anual.

2: Cambios benignos: control anual.

3: Hallazgos probablemente benignos: estudios de control $(6,12,18,24$ meses); malignidad < $2 \%$.

4: Anormalidad sospechosa: biopsia; malignidad 23-34\%.

5: Altamente sugestivo de malignidad: biopsia; malignidad $81-97 \%$.

6: Malignidad conocida: control.

La categoría 2 (cambios benignos) indica que en las imágenes mamográficas presentes se encuentran hallazgos anormales, pero con $100 \%$ de certeza de benignidad y un riesgo de malignidad de $0 \%$, por lo que no requiere estudios complementarios. Se incluyen lesiones con densidad grasa (radiolúcidas), macrocalcificaciones, microcalcificaciones puntiformes, ganglios intramamarios e imágenes categorizadas como probablemente benignas en estudios previos y estables en el seguimiento. La recomendación es continuar con tamizaje mamográfico (Figuras 4a, 4b, 4c, 4d, 4e, 4f).

En la categoría 3 (hallazgos probablemente benignos) en general se incluyen tres tipos: conjuntos de microcalcificaciones con baja sospecha (puntiformes), asimetrías focales no palpables y nódulos de densidad baja a intermedia, de contornos regulares. Con un riesgo de malignidad menor al $2 \%$, la recomendación es realizar control mamográfico a los seis meses, la cual se puede repetir a los meses 12,18 y hasta un máximo de 24 meses, pero en cualquier momento del seguimiento se puede reclasificar (Figura 5). 


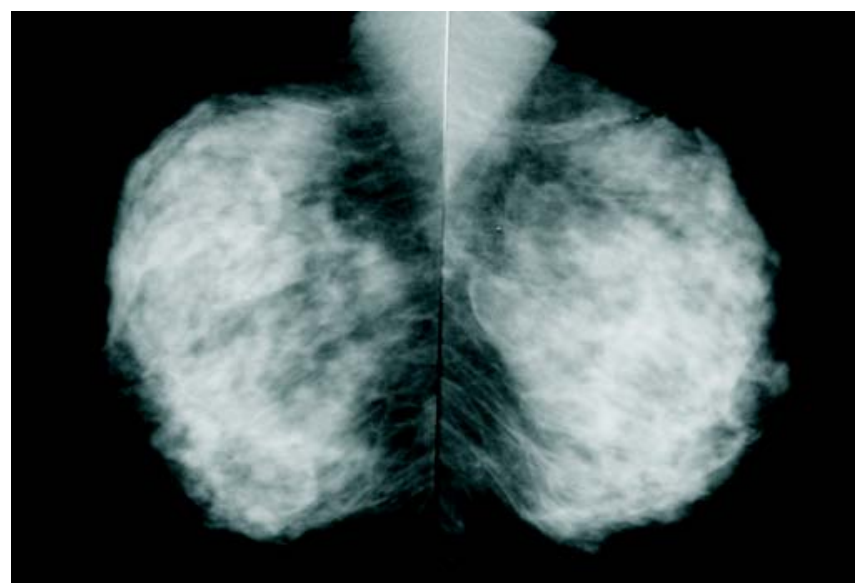

Figura Ia. BIRADS 0: parénquima mamario denso que oculta lesiones focales.

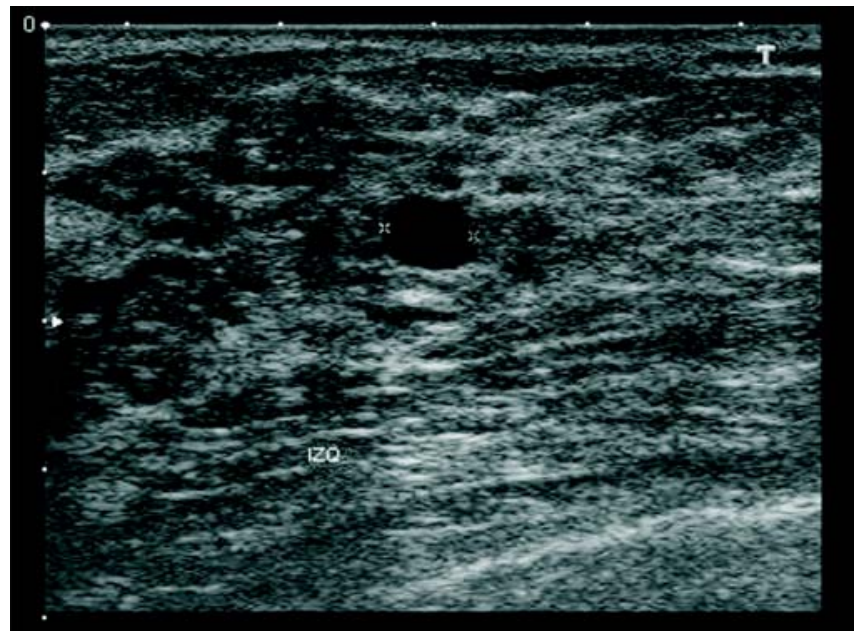

Figura Ib. BIRADS 0: el complemento ecográfico identificó lesiones quísticas simples.

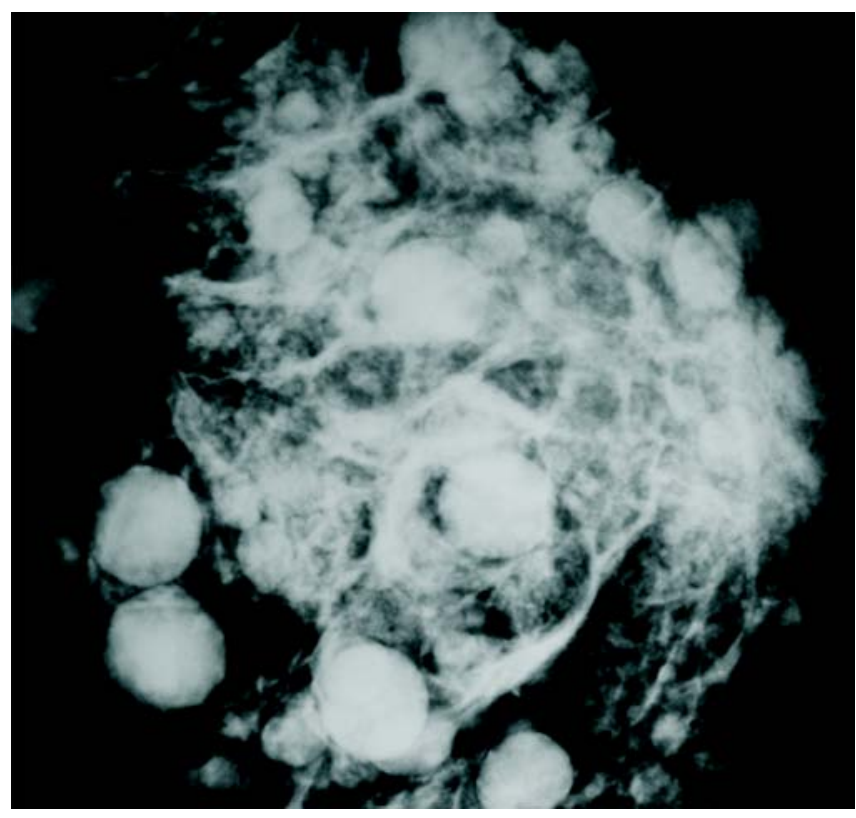

Figura 2a. BIRADS 0: múltiples nódulos mamarios inespecíficos en mamografía.

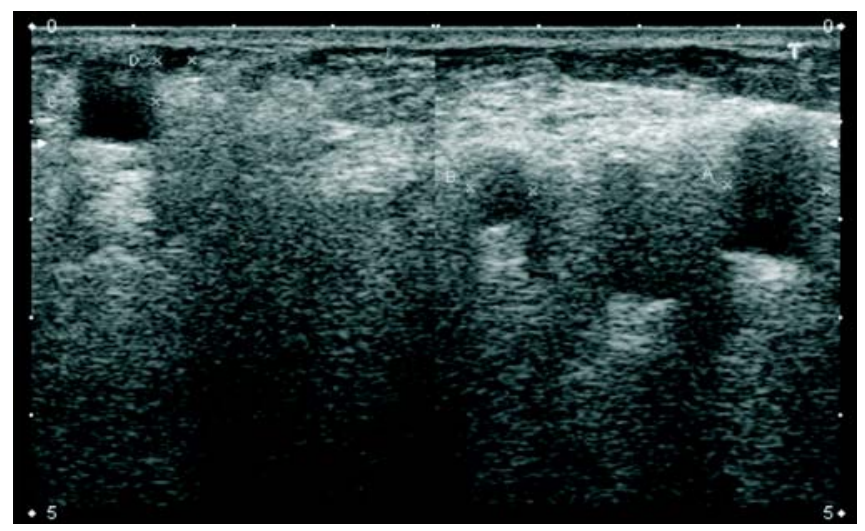

Figura 2b. BIRADS 0: nódulos sólidos hipoecoicos dispersos, con antecedente de inyección "estética" de biopolímeros.

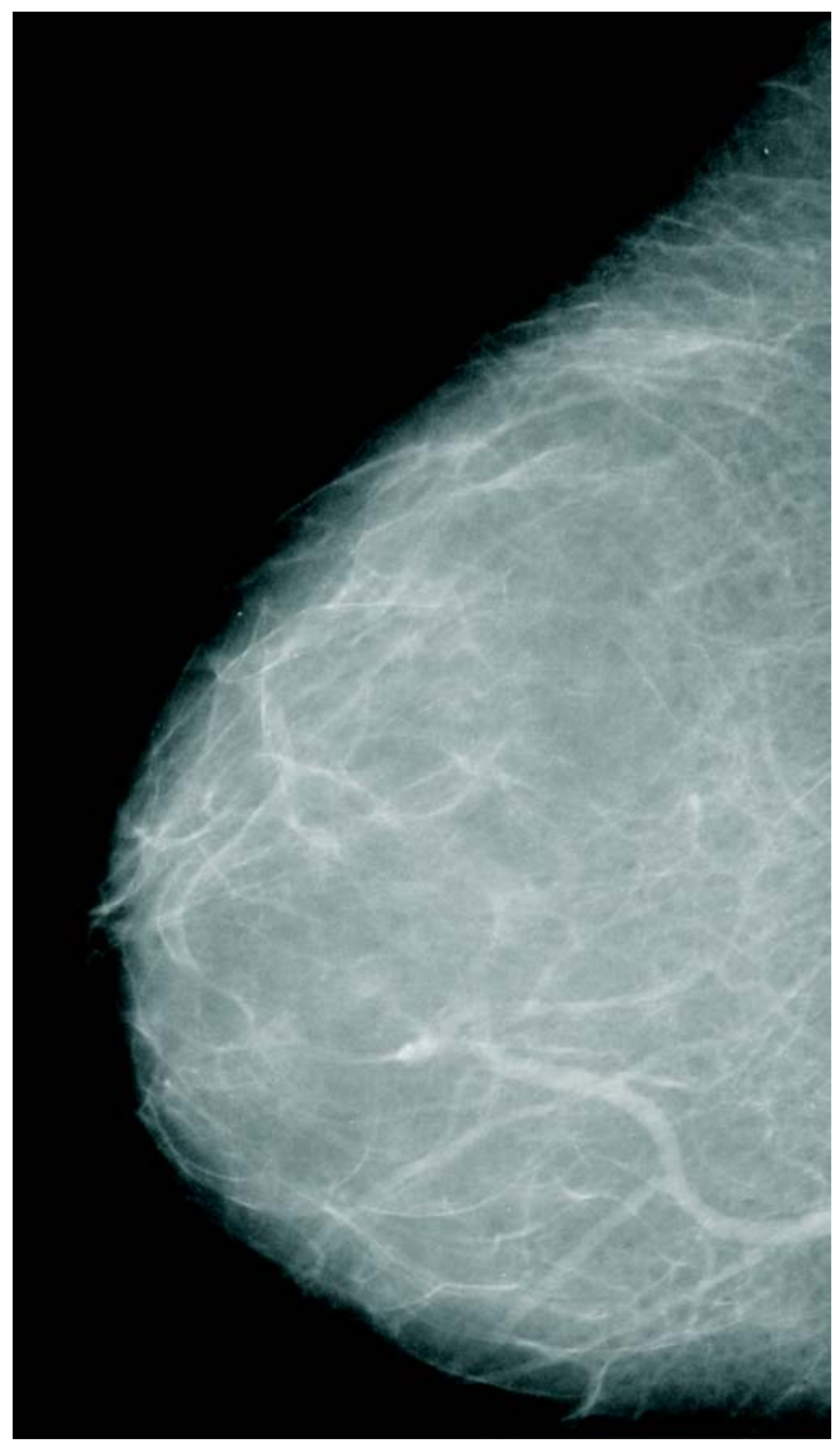

Figura 3. BIRADS I: parénquima mamario homogéneo, sin lesiones focales. 


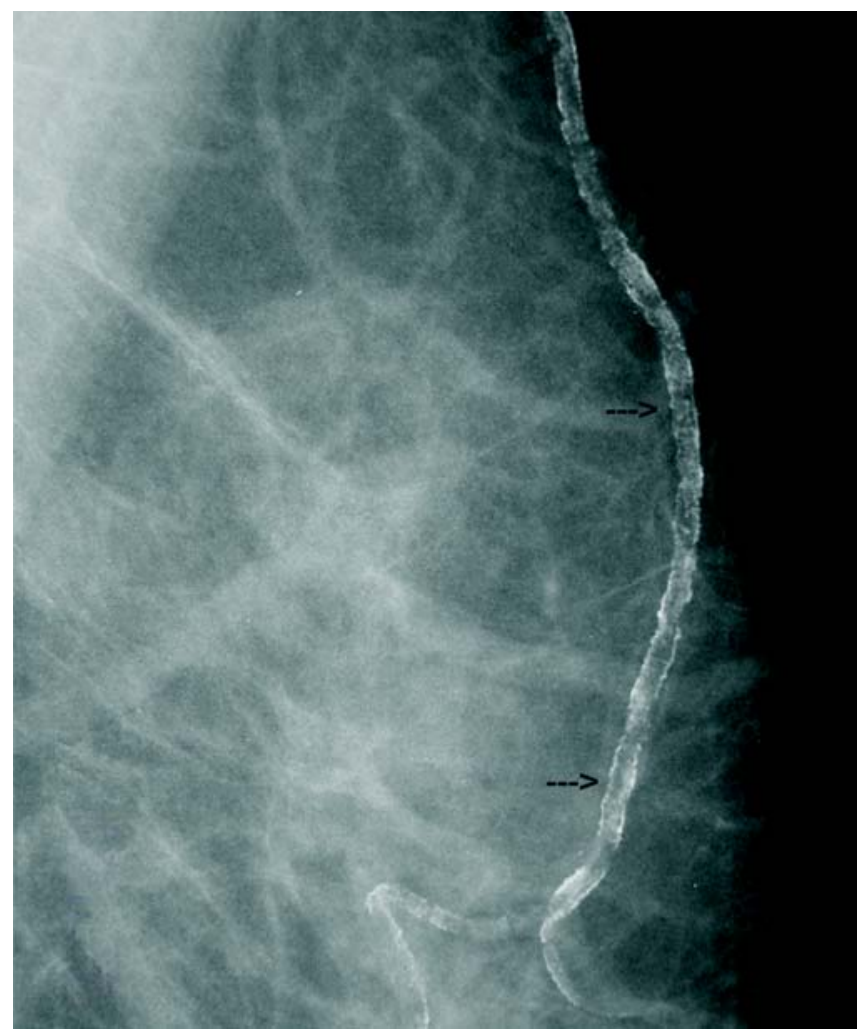

Figura 4a. BIRADS 2: ateromas.

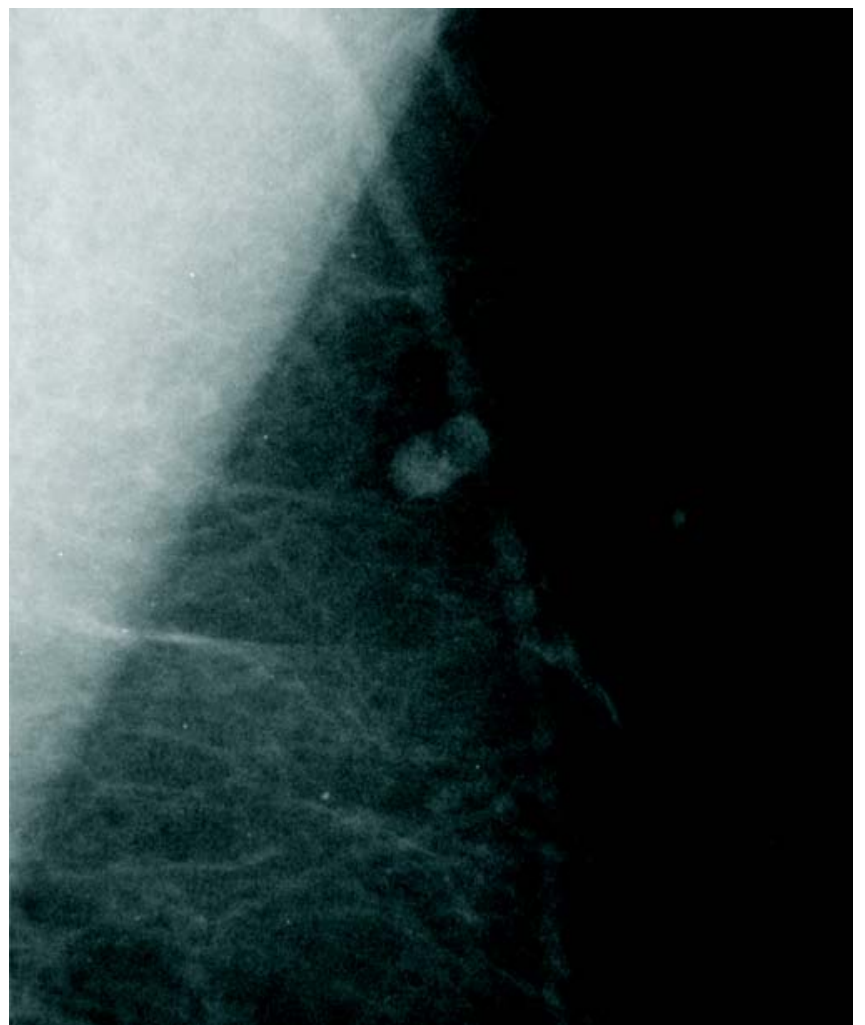

Figura 4b. BIRADS 2: nódulo ovoide arriñonado con centro graso, en vecindad a estructura vascular por ganglio intramamario.

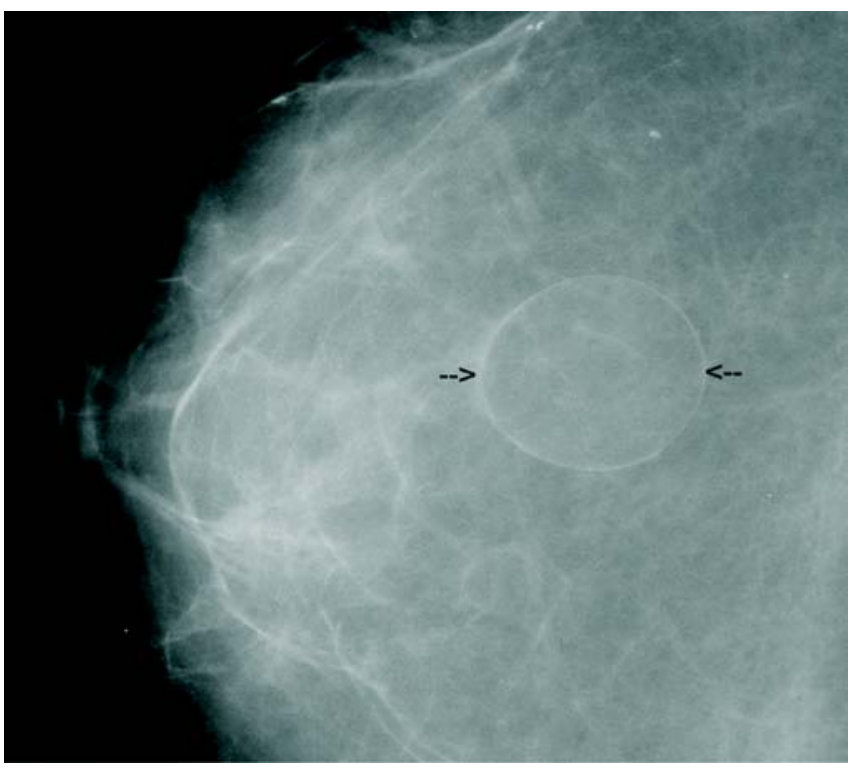

Figura 4c. BIRADS 2: quiste oleoso.

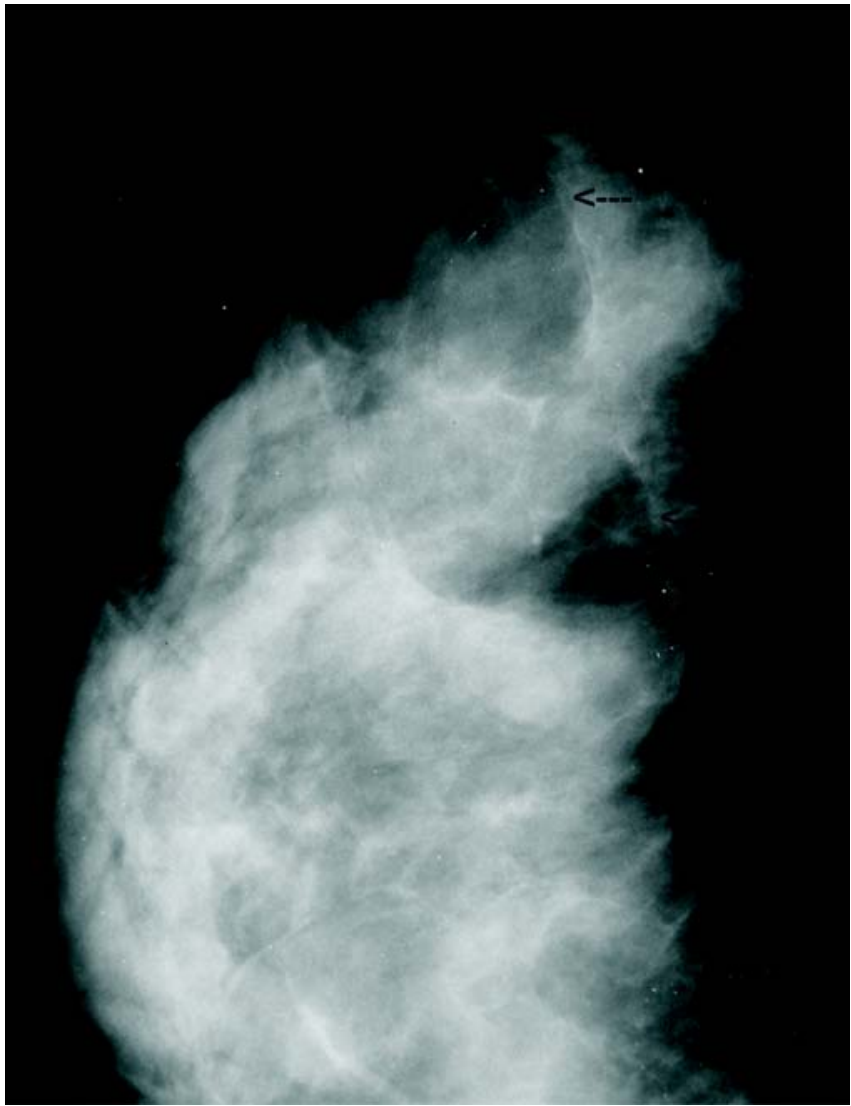

Figura 4d. BIRADS 2: lesión radiolúcida lobulada (flechas) por lipoma. 


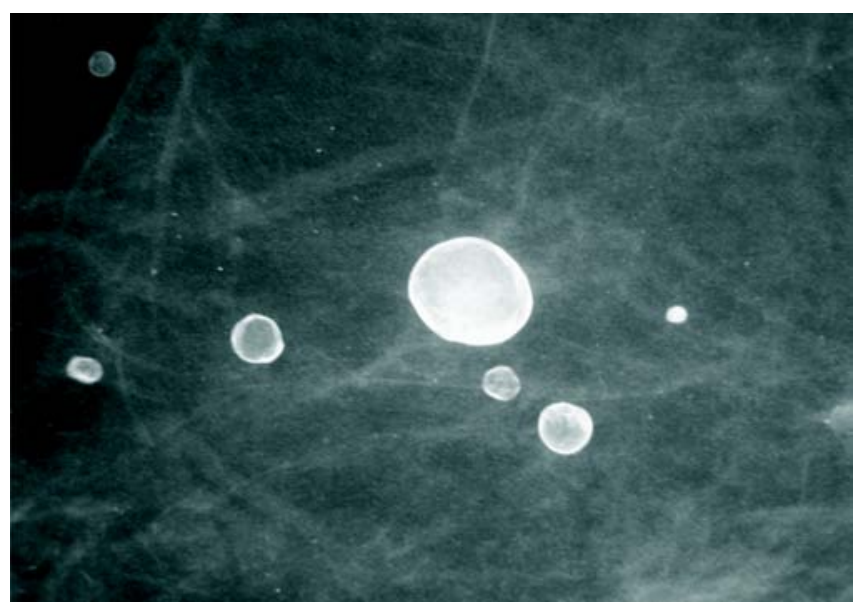

Figura 4e. BIRADS 2: macrocalcificaciones con centrorradiolúcido.

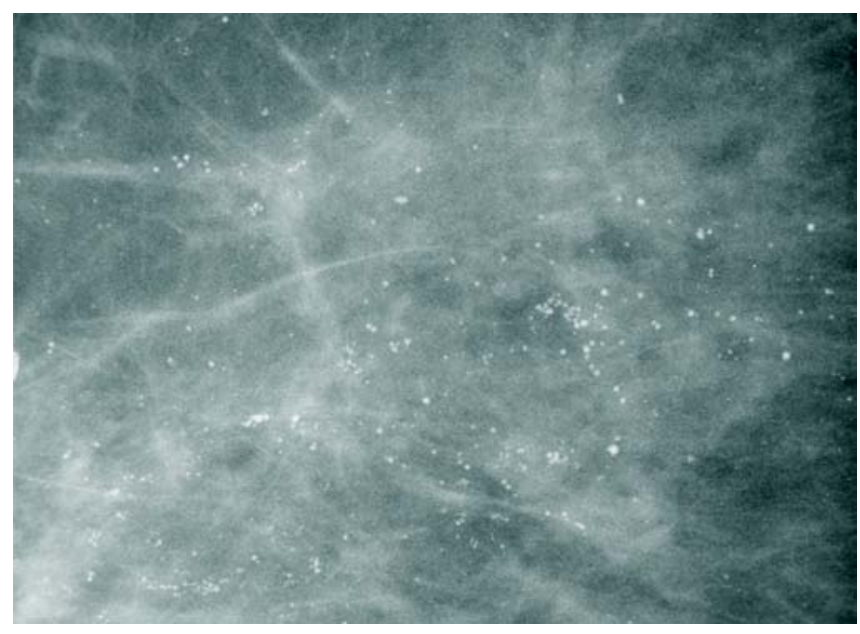

Figura 4f. BIRADS 2: múltiples microcalcificaciones puntiformes dispersas benignas por adenosis.

\section{Categoría 4 (hallazgos sospechosos de anormalidad)} en ella se consideran características como agrupaciones de microcalcificaciones heterogéneas, nódulos densos de contornos borrosos, distorsiones arquitecturales con centro radiolúcido o isodenso. Implica como recomendación biopsia trucut, con un riesgo de malignidad de $24-34 \% \%^{7,8}$ (Figuras 6a, 6b y 6c).

La categoría 5 (hallazgo sugestivo de malignidad): es el mayor nivel de preocupación, ya que implica un riesgo de malignidad de $81-95 \%$. En general se reserva para nódulos espiculados densos, con o sin microcalcificaciones, o para agrupaciones de microcalcificaciones pleomorfas sin nódulo asociado (Figuras $7 \mathbf{a}$ y $7 \mathbf{b}$ ). En una misma mamografía se pueden identificar varia- dos hallazgos que dan diferentes categorías BIRADS, uni o bilaterales, pero el concepto final siempre toma uno solo, el BIRADS de mayor valor sin importar la lateralidad. ${ }^{1,2}$ Los hallazgos axilares no afectan la categorización BIRADS, pero es desafortunado que el manual no establece el límite a tomar entre axilar y glándula mamaria. Por último, las recomendaciones dadas en una categorización BIRADS no se deben tomar como ataduras y ante un reporte BIRADS 1 ó 2 pero con signos clínicos claros de masa, se deberán realizar los estudios complementarios de rigor.

\section{Auditoría}

Se divide en básica y avanzada, la primera es obligatoria en los requerimientos del MQSA y la segunda opcional. Se describen dos secciones en las que se establecen los datos que deben ser recopilados para permitir desarrollar por cada radiólogo su rendimiento a través de una auditoría clínicamente relevante. Implica un gran esfuerzo tanto del radiólogo como del centro diagnóstico, ya que se necesita recopilar un grupo de datos en unos formatos propuestos y suministrados en el mismo manual BIRADS y luego su análisis. Hay que comparar los valores obtenidos con los normales esperables que se especifican en el mismo manual. Se deben realizar al menos cada mil mamografías. Los principales valores obtenidos son sensibilidad, especificidad, valor predictivo positivo y tasa de cánceres en estadio 0-1 (Tabla 4).

\begin{tabular}{|l|c|}
\hline \multicolumn{2}{|c|}{ Tabla 4. Auditoría clínicamente relevante, } \\
valores esperados \\
\hline Cánceres diagnosticados por cada I.000 & $2-10$ \\
\hline Ganglios linfáticos positivos & $<25$ \\
\hline Tumores estadio 0 ó I & $>50$ \\
\hline Tumores diagnosticados - cáncer mínimo & $>30$ \\
\hline VPP al recomendar BX & $25-40$ \\
\hline Tasa de nuevas citas & $<10$ \\
\hline Sensibilidad & $>85$ \\
\hline Especificidad & $>90$ \\
\hline
\end{tabular}




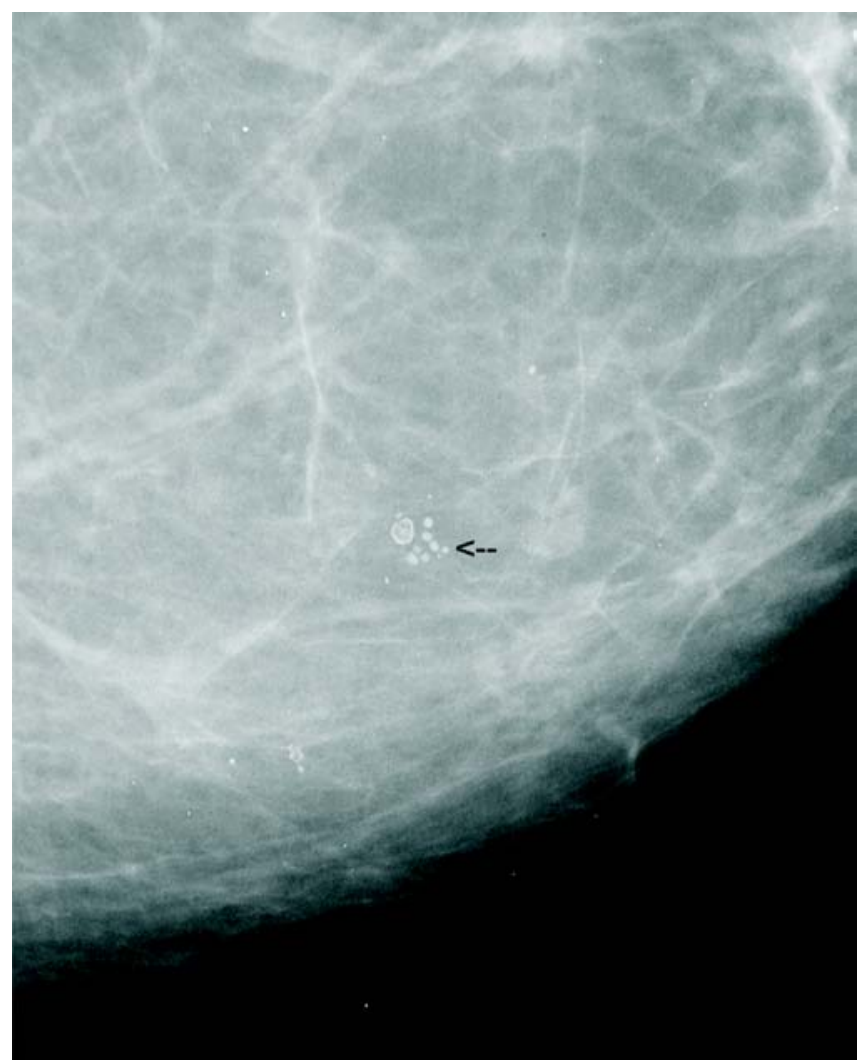

Figura 5. BIRADS 3: agrupación de microcalcificaciones monomorfas con grado de sospecha intermedia.

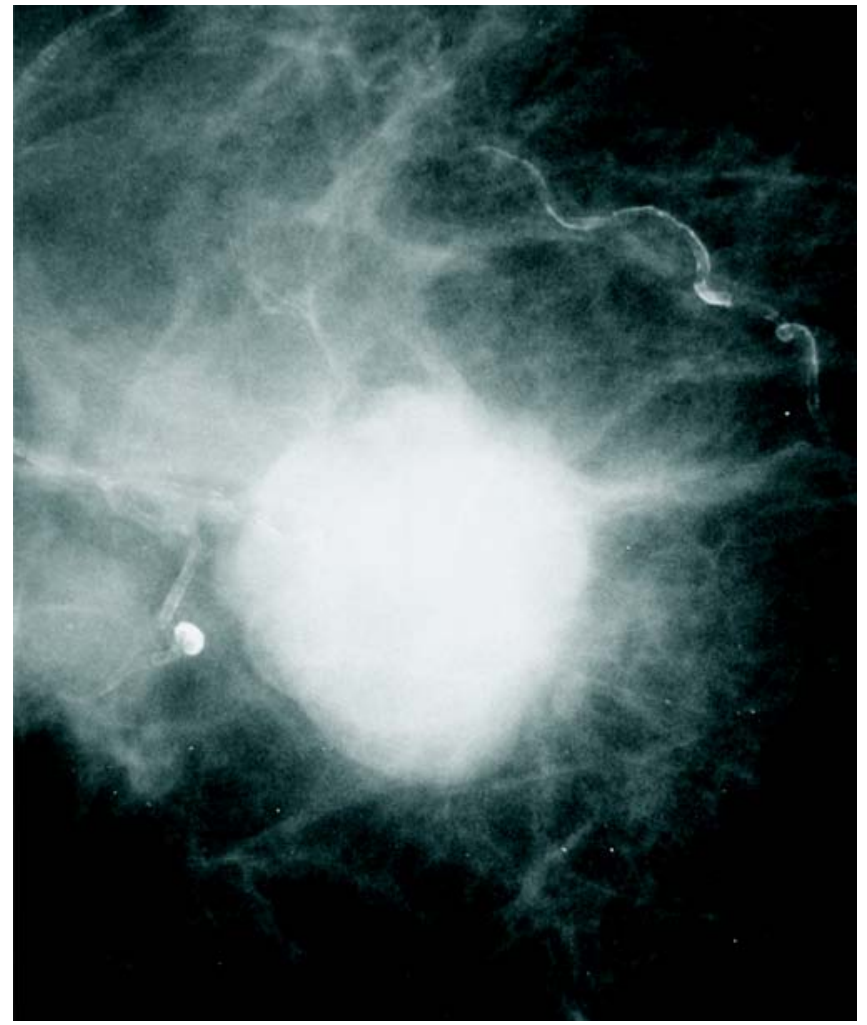

Figura 6a. BIRADS 4: nódulo de contorno borroso por cáncer ductal invasivo.

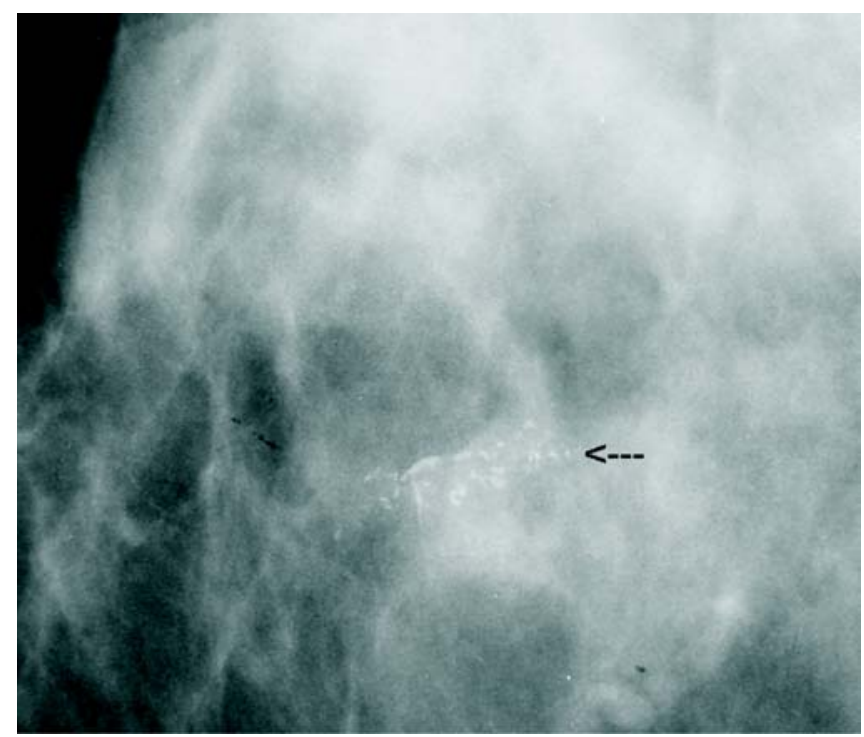

Figura 6b. BIRADS 4: microcalcificaciones amorfas agrupadas por cáncer in situ.

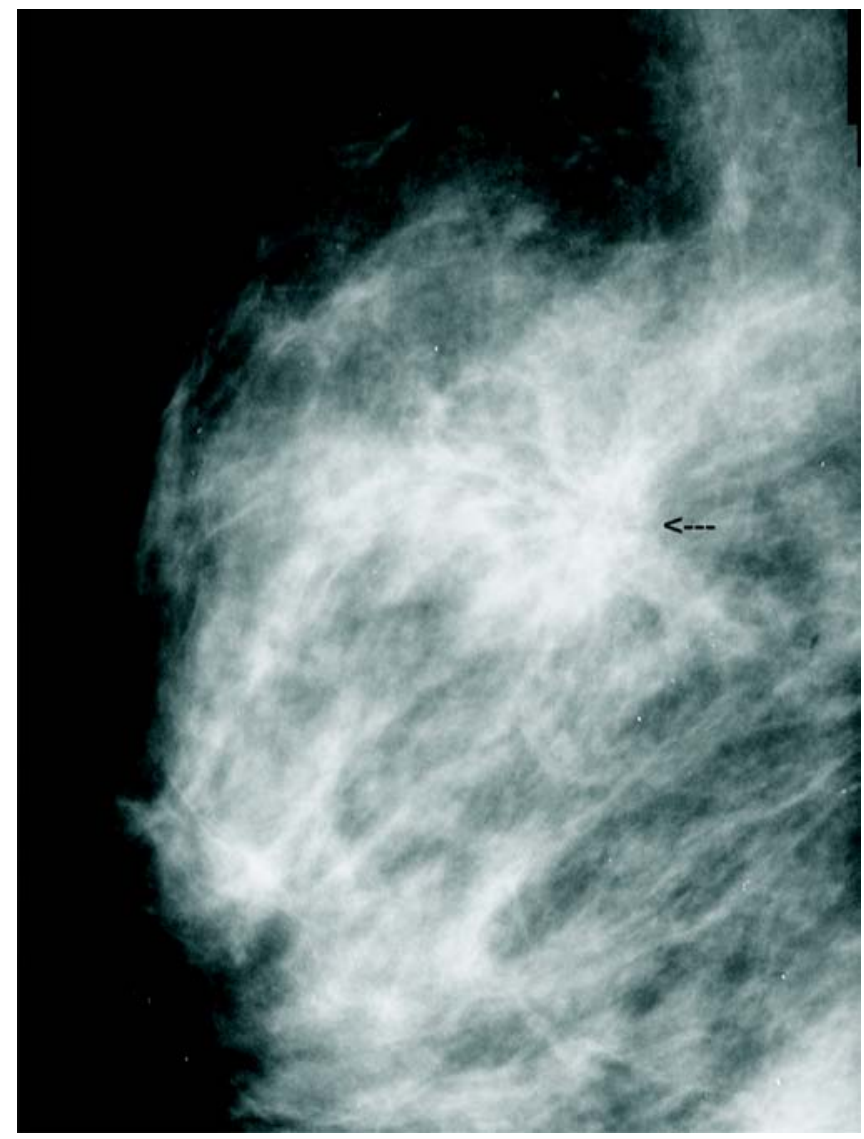

Figura 6c. BIRADS 4: distorsión de los ligamentos de Cooper sin nódulo por cicatriz radiada. 


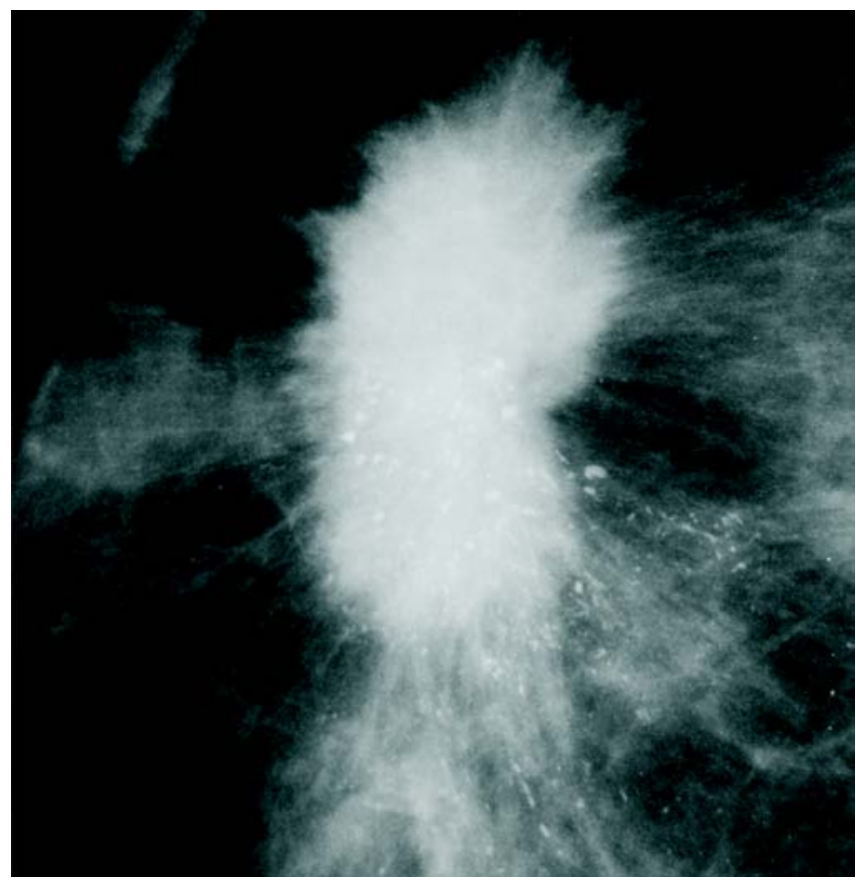

Figura 7a. BIRADS 5: nódulo denso espiculado, irregular por cáncer ductal invasivo.

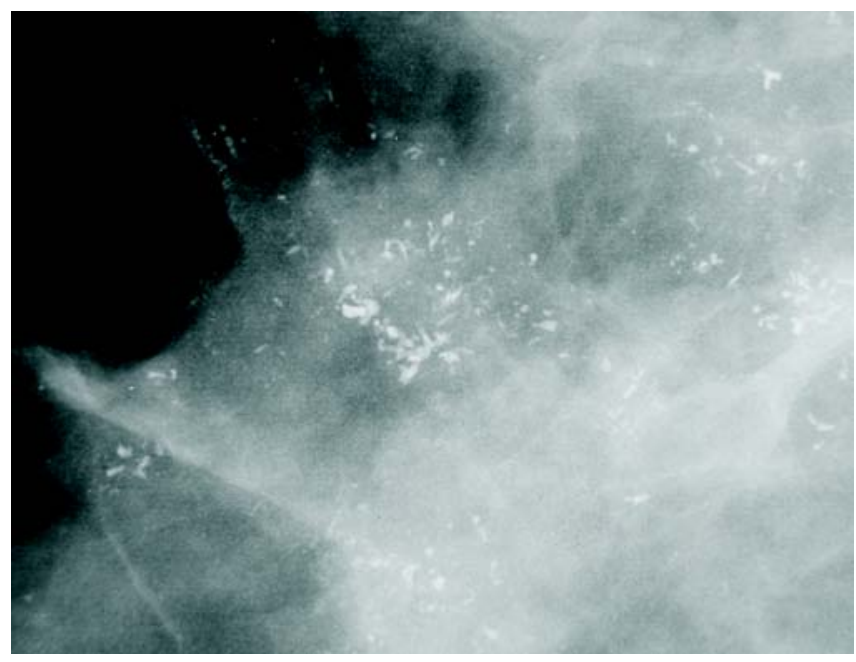

Figura 7b. BIRADS 5: microcalcificaciones pleomorfas de distribución segmentaría por cáncer in situ con necrosis.

\section{Discusión}

El manual BIRADS por todas las áreas que toca y en especial al ser cada día más una guía para los médicos de diferentes especialidades, debe salir del ámbito radiológico y tomarse por toda la comunidad médica que interviene en el manejo de las mujeres con patología mamaria. En el INC estamos en constante contacto con los diferentes médicos tratantes del país y a su vez en nuestro Departamento de Imágenes Diagnósticas recibimos multiplicidad de informes mamográficos de toda la nación, incluyendo Bogotá, y hemos encontrado dificultades similares a las descritas en la década de los ochenta en Estados Unidos.

Entre lo más destacable está la deficiencia en la calidad en la toma de los estudios mamográficos, en especial en lo referente al posicionamiento y revelado. Tampoco es inusual el inadecuado uso del léxico, la incongruencia entre la descripción del informe mamográfico y la categorización BIRADS, o entre la categorización y la recomendación emitida, llevando a confusión para el manejo de las pacientes. Estos problemas están aún por cuantificarse en nuestro medio. Es claro que un conocimiento más completo del manual y de sus objetivos, al igual que una mejor comunicación entre los médicos radiólogos y la restante comunidad médica, son unos de los principales pasos que se deben dar para un adecuado entendimiento del papel de la mamografía en la patología mamaria, que redundará en una mejor atención de nuestros pacientes.

\section{Referencias}

1. American College of Radiology. ACR BI-RADS: mammography. 4th ed Reston, VA: American College of Radiology; 2003

2. D'Orsi CJ, Newell MS. BI-RADS decoded: detailed guidance on potentially confusing issues. Radiol Clin North Am. 2007 Sep;45(5):751-63.

3. FDA. Mammography quality standards act [monografia en Internet]. Silver Spring, MD: FDA; 2010. [citado 27 Feb. 2010]. Disponible en: www.fda.gov/ Radiation-EmittingProducts/MammographyQualityStandardsActandProgram

4. Lehman C, Holt S, Peacock S, White E, Urban N. Use of the American College of Radiology BI-RADS guidelines by community radiologists: concordance of assessments and recommendations assigned to screening mammograms. AJR Am J Roentgenol. 2002 Jul;179(1):15-20.

5. Moreno L, Romero J. El informe mamográfico: el sistema BI-RADS. Rev Col Radiol. 1999: 10 (2):552-558

6. Tabar L, Dean P, Tot t. Mammographic-histologic correlation of tumor masses, asymmetric densities and architectural distorsion. In: Feig S, ed. Breast imaging: RSNA Categorical course in diagnostic radiology. Oak Brook, IL: RSNA; 2005. 9-29

7. Linver. M.BIRADS: guidance, reporting and communication. Breast Imaging: RSNA Categorical course in diagnostic radiology. 2005. 221-228

8. Libermann L, Menell JH. Breast imaging reporting and data system (BIRADS). Radiol Clin North Am. 2002 May;40(3):409-30

9. Instituto Nacional de Cancerología. Recomendaciones para la tamización y la detección temprana del cáncer de mama en Colombia. Bogotá: INC; 2006.

10. Murillo R, Diaz S, Sánchez O, Poveda C, et al. Pilot implementation of breast cancer early detection programs in Colombia. Breast Care. 2008: 3 29-32. 